\title{
Approaching patients with hyperreflectivity and perplexity: an empirical qualitative investigation
}

\author{
Abordando pacientes com hiper-reflexão e perplexidade: uma investigação \\ qualitativa empírica
}

Sidse Marie Arnfred, ${ }^{1,2}$ Paul Møller, ${ }^{3}$ Annette Sofie Davidsen 4

\begin{abstract}
Objective: Perplexity and hyperreflectivity are considered important aspects of self-disorders in patients with schizophrenia, yet knowledge of the appropriate psychotherapy for these patients is sparse. We aimed to explore how phenomenological psychologists or psychiatrists described their approach to these patients and their own emotional response when hyperreflectivity and perplexity emerged in therapy or consultations.

Methods: Four e-mail interviews with experienced clinical researchers within the field of phenomenology and schizophrenia were examined using a double hermeneutic qualitative analysis. Results: The informants offered reassurance by authority and the encouragement of sharing of experiences interlaced in the beginning of therapy. Later they went on relating expressions of hyperreflectivity and perplexity to emotions, life events and goals. They described feelings of admiration and professional recognition along with worry, insecurity and sadness.

Conclusion: The list of primary themes covers what might seem very basic therapeutic interventions. However, the careful and open-minded manner in which these were carried out was noteworthy. The double task of staying closely attuned to the patient's airy reflections and, at the same time, when the patient was ready for it, carefully making links to domains of the patient's everyday life, was clearly molded to patients with fragile attachment.
\end{abstract}

Keywords: Phenomenology, psychotherapy, schizophrenia, subjectivity, self-disorders

\section{Resumo}

Objetivo: A perplexidade e a hiper-reflexão são consideradas aspectos importantes dos desordens do self em pacientes com esquizofrenia, porém o conhecimento sobre o tipo mais apropriado de psicoterapia para esses pacientes é escasso. Nosso objetivo foi explorar como psicologistas fenomenológicos ou psiquiatras descrevem suas abordagens a pacientes aos pacientes e sua própria resposta emocional, quando a hiperreflexão e a perplexidade emergem durante a terapia ou as consultas.

Métodos: Quatro entrevistas feitas por e-mail com pesquisadores clínicos experientes na área de fenomenologia e esquizofrenia foram examinadas usando análise qualitativa dupla hermenêutica.

Resultados: Os informantes ofereceram confiança via autoridade e motivação para compartilhar experiências, interligadas, no início da terapia. Subsequentemente, eles seguiram relacionando expressões de hiper-reflexão e perplexidade a emoções, eventos de vida e objetivos. Eles descreveram sentimentos de admiração e reconhecimento profissional juntamente com preocupação, insegurança e tristeza.

Conclusão: A lista de tópicos primários engloba o que poderiam parecer intervenções terapêuticas muito básicas. No entanto, a forma cuidadosa e aberta como essas intervenções foram conduzidas é digna de nota. A tarefa dupla de estar atento às reflexões aéreas do paciente e, ao mesmo tempo, quando o paciente está pronto, cuidadosamente estabelecer relações com os domínios de sua vida diária, foi claramente moldada para pacientes com vínculo frágil.

Descritores: Fenomenologia, psicoterapia, esquizofrenia, subjetividade, desordens do self.

\footnotetext{
1 Psychiatry West, Mental Health Services, Slagelse, Region Zealand, Denmark. ${ }^{2}$ Department of Clinical Medicine, HEALTH, University of Copenhagen, Copenhagen, Denmark. ${ }^{3}$ Department of Mental Health Research and Development, Division of Mental Health and Addiction, Vestre Viken Hospital Trust, Drammen, Norway. ${ }^{4}$ The Research Unit for General Practice and Section of General Practice, Department of Public Health, HEALTH, University of Copenhagen, Copenhagen, Denmark.

Submitted May 14 2017, accepted for publication Nov 062017.

Suggested citation: Arnfred SM, Møller P, Davidsen AS. Approaching patients with hyperreflectivity and perplexity: an empirical qualitative investigation. Trends Psychiatry Psychother. 2018;40(3):216-225. http://dx.doi.org/10.1590/2237-6089-2017-0053
} 


\section{Introduction}

Psychosocial support, social skills training, psychoeducation, family interventions and medications are well established interventions in the treatment of patients with or at high risk of developing schizophrenia. Treatment is most often delivered in multimodal packages, where different problems are given priority along the course of treatment. Psychological interventions are known to be effective, ${ }^{1}$ and in these interventions it is considered relevant to engage in the patient's personal history of existential problems and the tentative communicative meaning of the symptoms. ${ }^{2}$ A flexible patient-centered approach is recommended. ${ }^{3}$ It has been emphasized that research should focus on describing elements of therapy in relation to subgroups of patients with schizophrenia. However, few guidelines exist where specific therapeutic approaches are matched with specific constellations of symptoms, resources or life histories. ${ }^{1,3,4}$

The focus on self-disorders in patients with schizophrenia has only recently led to specific suggestions for psychotherapy of the self-disordered patient. ${ }^{5}$ Hyperreflectivity and perplexity are among the core anomalous self-experiences of the patients with schizophrenia spectrum disorders, including the prodromal stages. ${ }^{6,7}$ Hyperreflectivity is an exaggerated self-monitoring of aspects of a person's own experience, which normally do not come into awareness. It is a "tendency to take oneself or parts of oneself or aspects of the environment as objects of intense reflection [...] and inability to react and behave spontaneously and carefree" (Parnas et al., ${ }^{8}$ p. 248). Hyperreflectivity is closely linked to perplexity. Perplexity is a bewildered or confused state of mind characterized by "a loss of common sense/lack of natural evidence" (Parnas et al., 8 p. 249). It is "... a loss or lack of automatic, prereflective grasp of the meaning of everyday events, situations, people and objects. [...] The reaction of the patient is of perplexity, curiosity, amazement and attempts to understand (through reflection) or to cope" (Parnas et al., 8 p. 249).

These self-disorders are not disturbances of selfimage, self-esteem or personal identity on a superficial social level, but rather a basic disruption in the sense of existing as an experiencing center or implicit subject-pole in the self-world relationship. ${ }^{9}$ Nelson et al. suggest that cognitive-behavioral therapy (CBT), with its emphasis on observing, challenging and restructuring previously "automatic" thoughts, might increase hyperreflectivity. Self-monitoring, which is included in the cognitive homework, could in this way lead to further distance rather than presence in the world. ${ }^{10}$ A review of psychodynamic psychotherapy for schizophrenia, centered around the problems of self-disorders, recommended to strengthen the patients' intersubjective presence and to increase their ability to verbalize their feelings. ${ }^{11}$ Likewise, the narrative approach, as described by Lysaker et al., ${ }^{12-}$ 14 emphasized intersubjective awareness as a way to strengthen first-person awareness. Other suggestions for psychotherapy approaches particularly wellsuited for self-disorders have also emerged. One review recommended phenomenologically informed psychotherapy, which could, however, also cover established therapies like narrative psychotherapy, cognitive-behavioral narrative therapy, interpersonalcognitive therapy, acceptance and commitment therapy, and mindfulness. ${ }^{15}$ Another study also suggested combining the phenomenological approach with other modalities. ${ }^{10}$ Thus, there is a need for finding the active ingredients in the new phenomenologically inspired approaches to psychotherapy of self-disorders. Casebased essays make a range of suggestions and the overarching theme in these studies is the presence of an interpersonal here-and-now relationship. ${ }^{13,14,16,17}$ No psychotherapy trials addressing hyperreflectivity or perplexity have been published. ${ }^{18}$ However, the difficulty of helping a person out of a hyperreflexive mode of being through a reflecting process of psychotherapy has been emphasized. ${ }^{17}$

During the last decades, phenomenological psychiatric research has witnessed a revival, leading to detailed clinical descriptions of patients' individual subjective experiences. ${ }^{6,7}$ Clinical researchers working in this field have accumulated experience with patients presenting with hyperreflectivity and perplexity. We carried out an empirical, qualitative study to explore the experience of the most clinically experienced among these researchers.

The aim of the study was to explore how phenomenological researchers describe their approach to patients when these distinct symptoms, hyperreflectivity and perplexity, emerge in a consultation or therapy.

\section{Methods}

\section{Design}

A qualitative approach was applied. The data material encompasses e-mail interviews conducted with four phenomenological researchers and analyzed by interpretative phenomenological analysis (IPA). ${ }^{19}$ The protocol was approved by the institutional board of Gestalt Akademin Scandinavia. 


\section{Informants}

Informant sampling was guided by the fact that only clinical researchers who were familiar with the conception of schizophrenia as a self-disorder would be able to delimit precisely situations with hyperreflectivity and perplexity and at the same time have experience with different interactions with this type of patient. Through the research network of the Center for Subjectivity Research in Copenhagen, a list of seven clinically experienced self-disorder researchers with a phenomenological approach was compiled. It was considered important that they had extensive experience with the recognition of self-disorder phenomena and had themselves conducted psychotherapy with schizophrenia patients. Four declined to participate, and one suggested another informant, who was not originally known by the researchers. Eventually, four clinical researchers were included, three males and one female. They were informed by e-mail of the study objective and methods, and they provided written consent of participation as informants. The informants all held positions in psychiatry, although at the time of the study their main function was research at a senior level, and they had less face-to-face patient contact. The researchers' original psychotherapeutic training was along variable frames of reference, but all had integrative approaches. The researchers were of different nationalities. Consequently, the interviews were conducted by e-mail in English.

\section{Interviews}

The phenomenological researchers were interviewed by e-mail about what they did when a patient with schizophrenia in the course of psychotherapy appeared hyperreflecting and/or perplexed, and what they thought and felt in the therapeutic situation. The e-mail interviews were conducted at time frames that suited the informants.

In the invitation sent to the informants, and in the interview set-up, we followed recommendations for e-mail interviews in qualitative research. ${ }^{20} \mathrm{E}$-mail interviews have drawbacks compared to face-to-face interviews, particularly due to the lack of spoken language, emotionality and asynchrony in responses, which could spur insecurity in the interviewer about the progress. ${ }^{21,22}$ The lack of emotional expressions was partly circumvented by the use of emoticons and expressive formatting. ${ }^{20,22}$

A guide of pre-phrased questions and prompts was created. The informants were asked to describe situations where hyperreflectivity was notable, and give detailed accounts of the patient, the context, their own feelings and their therapeutic actions. The interview guide was not followed if the exchanges demanded clarifying questions. The interviews were conducted across 2-6-week periods. When an interview was completed, the entire e-mail including all exchanges was transposed leading to a chronological arrangement of questions and responses. ${ }^{22}$

\section{Data analysis}

Interview data were analyzed following the phenomenological-hermeneutic tradition, i.e., focusing on the description and interpretation of interview material. ${ }^{23}$ The researcher's effort was to make sense of the informants' reflections, and to understand the reasoning and actions taken during the informants' interactions with the patients. In doing so, the process involved a double hermeneutic interpretation. The patients in therapy were trying to make sense of their life world, and the informants were trying to make sense of their patients' life world. To capture the complexity of the reflections of the informants, the interview material was analyzed using IPA. ${ }^{19}$ The text was read trying to grasp the situation described and the experience of the informant. ${ }^{24}$ The IPA procedure recommended for small sample sizes was followed, i.e., after the analysis of the first interview, the emergent themes were recognized and these themes were kept in the foreground when the subsequent interviews were analyzed to maximize the recognition of similarities and differences. ${ }^{19}$ Directories of phrases were compiled and themes were clustered. When the analysis was completed, a final table of themes for all four informants was produced. The emergent themes are presented as a narrative account supported by quotations.

\section{Ethics}

The present study did not interfere with the therapy of patients and it was not necessary to reveal the identity of the patients to the researchers. The informants were invited to participate in e-mail interviews and they were free to decline, which is in line with suggestions for ethical conduct in e-mail research. ${ }^{20,21}$

\section{Results}

Three themes clearly distinguished themselves as important active ingredients in the meeting between the informants and the patients. Participants described that these phenomena emerged in a specific sequence across the sessions with patients. Reassurance by authority and the encouragement of sharing of experiences and thoughts were described as interlaced in the beginning. Only later, the informants went on to 
relating expressions of hyperreflectivity and perplexity to emotions, life events and goals. Table 1 lists the quotes related to these themes. The informants described both negative and positive feelings and thoughts in the meeting with the patients. Furthermore, they described admiration for the patient, professional confirmation, worry and insecurity about their own abilities, and sadness. Table 2 lists the quotes related to the informants' feelings.

\section{Giving reassurance}

The informants explained that quite early in the meeting with the hyperreflecting patient they reassured the patients that they were not the only ones having these thoughts; that they were not necessarily going crazy and that it was possible to get treatment and relief. The informants experienced that the impact of this reassurance was increased by the simultaneous explicit statement of their expertise: "And my signaling

Table 1 - Quotes related to psychotherapy activities

\begin{tabular}{|c|c|c|}
\hline Reassurance by authority & Encouragement of sharing & $\begin{array}{l}\text { Relating hyperreflectivity and perplexity } \\
\text { thoughts to emotions, life and goals }\end{array}$ \\
\hline $\begin{array}{l}\text { I think he was relieved to see that } \\
\text { I apparently was familiar with the } \\
\text { difficulties he presented, that I did not } \\
\text { take him for completely mad, and that } \\
\text { I envisaged a psychotherapy. (P1, 67) }\end{array}$ & $\begin{array}{l}\text { I tried to help him express them as } \\
\text { well as he could. (P1,121) }\end{array}$ & $\begin{array}{l}\text { I also specifically evoked with him the question of } \\
\text { identity. (P1, 125) }\end{array}$ \\
\hline $\begin{array}{l}\ldots \text { and tried to reassure him by a) } \\
\text { showing that } I \text { knew something of } \\
\text { these phenomena and } b \text { ) telling him } \\
\text { he was not the only person to suffer } \\
\text { that. ( } P 1,122)\end{array}$ & $\begin{array}{l}\text { I always try, during the interview, } \\
\text { to help the patient formulate these } \\
\text { difficulties, and to convey the idea } \\
\text { that it is not so uncommon as they } \\
\text { generally think. (P1, 255) }\end{array}$ & $\begin{array}{l}\ldots \text { to help him put some things more clear in his life, } \\
\text { his projects and his relations to others. }(P 1,129)\end{array}$ \\
\hline $\begin{array}{l}\text { I tried to reassure her by saying that } \\
\text { these feelings of hyperreflectivity and } \\
\text { perplexity, though generating anxiety, } \\
\text { were shared by several other persons. } \\
(P 1,216)\end{array}$ & $\begin{array}{l}\ldots \text { giving the patient the opportunity } \\
\text { to speak and to share about these } \\
\text { phenomena lessens the suffering. ( } P 1 \text {, } \\
314 \text { ) }\end{array}$ & $\begin{array}{l}\text { I tried to make some links with other things I knew } \\
\text { from his family. (P1, 145) }\end{array}$ \\
\hline $\begin{array}{l}\text { I also always explicitly give back to } \\
\text { the patients a commentary about the } \\
\text { core phenomena. (P2, 54) }\end{array}$ & $\begin{array}{l}\ldots \text { the ability to conceive or interpret } \\
\text { questions and messages from the } \\
\text { patient FIRST AND FOREMOST quite } \\
\text { literally - at least checking it explicitly } \\
\text { out - with an attitude of genuine } \\
\text { interest and receptivity, is helpful. } \\
(\mathrm{P} 2,90)\end{array}$ & $\begin{array}{l}\ldots \text { the goal-directed sorting out [informant's bold } \\
\text { formatting]. (P2, 258) }\end{array}$ \\
\hline $\begin{array}{l}\text { I think I was able to explain not too } \\
\text { complicated what was the unreality all } \\
\text { about. }(P 2,175)\end{array}$ & $\begin{array}{l}\ldots \text { it is often a clinical challenge to } \\
\text { slow down "therapeutic" responses, } \\
\text { so that the unusual expressions can } \\
\text { have time and space to manifest } \\
\text { [informant's bold formatting] clearly } \\
\text { without interpretations. (P2, 240) }\end{array}$ & $\ldots$ help to create new meaning. $(P 3,97)$ \\
\hline $\begin{array}{l}\text { And my signaling that the experiences } \\
\text { were known from others and the } \\
\text { literature, and in some sense } \\
\text { explicable. (P2, 187) }\end{array}$ & $\begin{array}{l}\ldots \text { the "phenomenological attitudes" } \\
\text { of an active interest, the opening } \\
\text { wondering [informant's bold } \\
\text { formatting]. (P2, 255) }\end{array}$ & $\begin{array}{l}\ldots \text { attempt to give or find meaning to this happening. } \\
(\mathrm{P} 3,223)\end{array}$ \\
\hline $\begin{array}{l}\ldots \text { to make it clear for the patient that } \\
\text { this kind of experiences are not so } \\
\text { unique and private as they might fear. } \\
(\mathrm{P} 2,278)\end{array}$ & $\begin{array}{l}\text { He is accepted as the one he is, with } \\
\text { all the strange experiences included. } \\
(P 2,262)\end{array}$ & $\begin{array}{l}\text { Then I often try to make the patient's experience of } \\
\text { anxiety, confusion, depression, or what it might be, } \\
\text { understandable by seeing this in connection with his } \\
\text { troublesome experience, new meaning and his history } \\
\text { (in the latest period). (P3, 304) }\end{array}$ \\
\hline $\begin{array}{l}\text { I think sometimes patients find it } \\
\text { relieving to know that someone at } \\
\text { least recognizes the things they are } \\
\text { going through, and that perhaps there } \\
\text { is actually some knowledge that might } \\
\text { help others understand them or even } \\
\text { help them. (P4, 64) }\end{array}$ & $\begin{array}{l}\text { The striving to give WORDS } \\
\text { [informant's bold formatting] to } \\
\text { very strange feelings, thought } \\
\text { transformations, voice-like } \\
\text { experiences etc. (through the } \\
\text { hermeneutic question-and-answer } \\
\text { cycles) is of course therapeutic. (P2, } \\
264 \text { ) }\end{array}$ & $\begin{array}{l}\text { (For example help him to see how different bodily } \\
\text { experiences as emotions, sounds, sights are } \\
\text { connected, appear together and belong to himself). } \\
(\mathrm{P} 3,360)\end{array}$ \\
\hline
\end{tabular}


that the experiences were known from others and the literature and in some sense explicable." They said that it was considered a relief for the patients that the symptoms had been observed in others previously: "to reassure him by a) showing that I knew something of these phenomena and b) telling him he was not the only person to suffer that." However, the patients could also feel slightly offended by the notion that they were not as special as they thought or by the use of too "diagnostic" language.

An important aspect of the reassurance was experienced to be the ability of the informant to install hope in the patient: a hope that they would be able to find acknowledgement and understanding by others and/ or within themselves through therapy or relief through medication and psychosocial support: "that they can be understood and get help is always important."

\section{Encouraging the sharing of experiences}

The informants emphasized the relative relief reported by and observed in the patients when they had encouraged the patients to share their experiences and met them with empathy and understanding: "giving the patient the opportunity to speak and to share these phenomena lessens the suffering." It was stressed that an open, wondering attitude was important, while it was

Table 1 (cont.)

\begin{tabular}{|c|c|}
\hline Reassurance by authority & Encouragement of sharing \\
\hline $\begin{array}{l}\text { At same time, some patients may feel } \\
\text { a bruising of their narcissism, since } \\
\text { they liked to think of themselves } \\
\text { as unique and having very special } \\
\text { insight. (P4, 69) }\end{array}$ & $\begin{array}{l}\text { I do respond to the patients by } \\
\text { exploring their experiences and } \\
\text { actively use examples to convey my } \\
\text { understanding of what he is saying. } \\
(P 3,52)\end{array}$ \\
\hline $\begin{array}{l}\text { I can remember, once or twice, when } \\
\text { using abstract, perhaps diagnostic } \\
\text { sounding language, seemed to make } \\
\text { the patient recoil slightly. (P4, } 81 \text { ) }\end{array}$ & $\begin{array}{l}\text { I try to re-establish relational contact } \\
\text { - intersubjectivity, that again help } \\
\text { the patient to share, and make } \\
\text { understandable in an intersubjective } \\
\text { context, their feelings, thoughts - } \\
\text { experience of their inner and outer } \\
\text { world. (P3, 71) }\end{array}$ \\
\hline
\end{tabular}

... and that we would have to work, in the coming months, on how she would nevertheless progressively find her way. (P1, 220)

... that they can be understood and get help is always important. (P3, 64)

The experience of being understood, re-establish (intersubjective) relational contact. (P3, 97)

... motivate him to go on telling about his experiences. (P3, 216)

I try to grasp/understand his experience that he shares with me both by words and eye/body movements. I do comment on what I see and how I see it. (P3, 275)

... not treating what the patient was saying as if it were word salad or poverty of content of speech. (P4, 77)

I, to a certain degree, manage to kind of build a "bridge" between us - or in other words experience that we create new (shared) meaning between us. (P3, 237)

I encouraged him to talk about these experiences. (P4, 45)
Relating hyperreflectivity and perplexity thoughts to emotions, life and goals

About the use of a phenomenological focus, - this group of patients are very insecure in relation to their own experience and therefore I see it as very important (but also difficult) not to jump to conclusions based more on my understanding rather than of what he really says... (P3, 400)

I made links between his expressions of hyperreflectivity and perplexity and situations which upset him in his life and perspective for the future. (P1, 175)

I do share my hypothesis with him as such, which, he in return recognizes as a description of his experience that makes meaning for him. (P3, 212)

I try to "hold" him with words by listening carefully to his descriptions of his experiences in detail and share my understanding of what he has told me and/ or constructing meaning of his experiences continually (but not fast) as he describes them. (P3, 199)

I do think that by referring to the patient's expressions (in words or body movements), focus on this observation, kind of mirroring/enlarge it, and then describe this in other words independent of the modality it in the first place was expressed in, we in a way create new meaning or at least help the patient to experience himself in a more meaningful way. (P3, 288)

I try to relate these fundamental phenomena of disturbed identity (or these phenomena of disturbed fundamental identity...) to the life experience of the patient, his/her self-projection in the future, family's history, etc. (P1, 285) 
considered a challenge not to jump into interpretation of thoughts: "it is often a clinical challenge to slow down 'therapeutic' responses, so that the unusual expressions can have time and space to manifest [informant's bold formatting] clearly without interpretations." The phenomenological stance was mentioned and focus was on global acknowledgement of the patients, including their painful or strange thoughts: "He is accepted as the one he is, with all the strange experiences included." By sharing their inner life, the patients were considered to regain contact with and access to the intersubjective world, and this was described as increasing their understanding of themselves: "I, to a certain degree, manage to kind of build a 'bridge' between us - or in other words experience that we create new (shared) meaning between us." One informant pointed to the

Table 2 - Quotes related to the informants' feelings

\begin{tabular}{|c|c|c|c|c|}
\hline Admiration & $\begin{array}{l}\text { Professional } \\
\text { recognition }\end{array}$ & Insecurity & Worry & Sadness \\
\hline $\begin{array}{l}\text { I was amazed by } \\
\text { the richness of } \\
\text { the spontaneous } \\
\text { descriptions. (P1, 45) }\end{array}$ & $\begin{array}{l}\text { It was of course a } \\
\text { confirmation of the } \\
\text { diagnosis. (P1, 44) }\end{array}$ & $\begin{array}{l}\text {... certainly several of } \\
\text { my interventions were } \\
\text { superfluous. (P1, 242) }\end{array}$ & $\begin{array}{l}\text { I was somehow anxious } \\
\text { discovering how much his } \\
\text { lack of natural evidence } \\
\text { was pervading his } \\
\text { everyday life. (P1, 105) }\end{array}$ & $\begin{array}{l}\text { I don't think I was } \\
\text { directly concerned } \\
\text { about the patient, but } \\
\text { definitely felt sorry for } \\
\text { his situation, and had a } \\
\text { clear feeling that he was } \\
\text { in a painful situation. } \\
(\mathrm{P} 2,72)\end{array}$ \\
\hline
\end{tabular}

G. was wondering, in a He confirmed several sort of Kierkegaardian phenomena. $(\mathrm{P} 2,28)$ way. (P1, 136)

I was struck by the originality and unquestionable authenticity of his

She did talk about the things in a gifted way, and I wrote down a lot of what she said. (P2, 142)

... as well as considerable intellectual fascination. (P4, 44) This requires strong

... his highly unusual and courageous question. (P2, 77) question. (P2, 65)

... a glimpse of irritation, I had of course many briefly thinking that he intentionally tried to make the conversation non-important. (P2, 41)

... that I am able to help the patient in the way I have already described. focus and does take a lot of energy, but makes me feel a kind of relief when I am finished. (P3, 335)

I had a definite feeling of Praecox Gefühl. (P4, 43)

do worry about my own contribution; did I offer the patient good enough help? (P3, 84)

I do have this feeling that I am about to lose ground/fall if I am not careful. (P3, 98)

Some patients I speak with make me very anxious and almost exhausted when the patients finally leave. (P3, 327)

I do get the feeling that the relation is very fragile, but also very important. (P3, 340) speculations between sessions. (P1, 228)

I felt very sorry for her, it was easy to get a sense of how painful her situation was. (P2, 141)

I was rather worried by this situation, also because of a complicated family situation. (P1, 209)

I actually was concerned for this patient, mainly connected to a fear that she might take her own life, due to the enormous sufferings. (P2, 163)

I am always very aware of the danger of self harm/suicidal attempt. (P3, 43)

I am often deeply worried and think that we do have to offer the patients help in some way. (P3, 82)

And I am often worried about the possibility of self-harm/suicidal attempt. (P3, 86)

When he left I felt in a way relief and was not worried about him (as often when I meet patients like him). (P3, 241)
I often feel a strong pain. (P3, 40)

I do get the feeling of strong hopelessness, maybe caused by the experience of loss of meaning. ( $P 3,329)$ 
importance of including body movements as part of the patient's expression, although with some limitation. Body language was only brought into focus if the patients themselves seemed to be aware of it and it was relevant in the context: "I try to grasp/understand his experience that he shares with me both by words and eye/body movements. I do comment on what I see and how I see it."

\section{Relating expressions of hyperreflectivity and perplexity to emotions, life events and goals}

The informants described the next phase in therapy as containing a very delicate and cautious linking of the issues of hyperreflection or perplexity with different aspects of the patients' life, including their emotions and future goals. Even within the sharing process, the therapist might assist in the clarification of the ideas and there was no hard-and-fast boundary between the two types of interactions. The manner in which this was done seemed somewhat different among the informants, and one of them described the difficulty of not overriding the patient: "this group of patients are very insecure in relation to their own experience and therefore I see it as very important (but also difficult) not to jump to conclusions based more on my understanding rather than of what he really says." Yet, the quest for meaning was in focus either by establishing connections between the patients' thoughts and family history, their present relations or sorting out their aims for the future: "I made links between his expressions of hyperreflectivity and perplexity and situations which upset him in his life and perspective for the future." Furthermore, establishing connections between different modalities of experiences in singular moments were experienced as creating meaning for the patient: "For example help him to see how different bodily experiences as emotions, sounds, sights are connected, appear together and belong to himself."

The informants stressed the importance of being careful if they made interpretations; always offering them as hypothetical.

\section{Informant's feelings}

The informant's admiration was quite obvious from the positive amazement (or even fascination) that was described either very directly or more indirectly by the way the patients were described: "G was wondering, in a sort of Kierkegaardian way." The admiration seemed to adhere both to the intellectual content of the patient's thoughts and to the lack of pretense in their presentation: "I was struck by the originality and unquestionable authenticity of his question." The informants also described the professional recognition that emerged from the satisfaction of recognizing the symptom pattern, and in so doing confirming the theories within which the informants worked. Nevertheless, the informants also expressed worry and professional insecurity about their abilities. The worry concerned the impact of the illness on the patient's relationships and the risk of self-harm or suicide. The informants said that this was felt in between sessions as worry and within sessions as anxiety: "I was somehow anxious discovering how much his lack of natural evidence was pervading his everyday life." The suffering of the patients evoked another type of tension. Part of it was the insecurity about the outcome: Was the help sufficient? Professional insecurity was found in specific statements; however, it could also be traced in the pervasive use of words such as "attempt to" and "try." Part of the tension seemed to be a kind of empathic anxiety, derived from mirroring the patient - "I get a bit anxious (probably because the patient's despair is so strong and obvious although he says he feels nothing)" - or perhaps from the informant's recognition of the limits of psychotherapy for this patient group. Lastly, the informants described sadness, which mainly seemed to be an empathic reflection of the hopelessness and loss of meaning expressed by the patients, although it also included the feeling of sympathy.

\section{Discussion}

\section{Understanding hyperreflectivity}

Within phenomenological psychopathology, hyperreflectivity is seen as the result of taking one's mental processes as an object for scrutiny and monitoring, processes that are normally automatic and tacit. It is seen as both a primary dysfunction of self-awareness and a coping mechanism, appearing concomitantly with perplexity. ${ }^{8}$ Patients with schizophrenia spectrum disorders may also present intellectualization or ruminations that do not have the characteristics of hyperreflectivity. The informants described the hyperreflecting patient's painfully unstable grasp on reality as one of the most notable features.

Some authors have assumed that "cognitive avoidance," manifested as thought disorder, obscurity of meaning and grandiose thinking are unconscious avoidance strategies, which makes it easier for the patient not to take themselves or the therapist seriously. In so doing, the patient is interpreted as creating a barrier to a real relationship, which they find intolerable, and the avoidance strategy serves the purpose of a defense mechanism. ${ }^{25}$ In contrast, selfdisorders must be understood as much more primordial 
and outside the patient's control. We suggest that it is more in line with the nature of self-disorders to understand hyperreflectivity as a kind of "sponge of thoughts and ideas," absorbing the drive that would in normal circumstances be spent in social engagement with the outside world.

\section{Recreation of meaning in the intersubjective space}

The careful formation of an empathic bridge between therapist and patient was the most distinct intervention for the hyperreflecting patient. This has in other studies been described as mutuality, rapport, interpersonal connectedness or shared partnership. ${ }^{14,16,17,26}$ When self-disorders were the core complaints, problems of intersubjectivity emerged as the core functional disturbance in the building of the therapist-patient relationship. Consequently, it has been suggested that the aim of psychotherapy for these patients is the experience of significant moments of contact, where the self is experienced through mirroring contact with another person. ${ }^{10,13,14}$ It is the recreation of meaning in the intersubjective space that leads to meaning within the self. $12,14,26$ Working towards this goal might evoke the patient's anxiety and subsequent withdrawal. ${ }^{10}$ The fear of this reaction could be the explanation for the informant's carefulness. In accordance with previous findings, the informants acknowledged that being present in the moment and attentive to the patient was the most important. Classifying symptoms or trying to modify them was not the goal. ${ }^{27}$ They showed a containing attitude, as previously phrased by Winnicott, ${ }^{1}$ yet they did so with an enhanced focus on targeted wondering. This is in line with Selzer et al.'s emphasis on the need to stay focused on the subjective experience of the patient without appraisal. ${ }^{25}$ The wondering, exploratory, positively curious attitude described by the informants, and elsewhere named sympathetic curiosity, ${ }^{26}$ is in accordance with these earlier suggestions, ${ }^{25}$ where the reciprocal stimulation of the patient's own curiosity has been mentioned as an important aspect. ${ }^{28}$

The special meaning of the sharing of experiences was emphasized. It was not just an exchange of separate stories. Sharing is the relatedness that occurs through special contact and dialog where the subjectivity of both participants is at play in a common, shared space. ${ }^{12-14}$ The informants also conveyed the difficulty and uncertainty they had in this sharing. This could be because the process includes an aspect of "congruent disintegration" of the therapist's inner world into the strange world that the patient shares with him. ${ }^{29}$ Nevertheless, Rosenbaum stated that the patient's world is understandable and that understanding is necessary to achieve the patients' engagement. ${ }^{27}$ Still, it is not possible to fully know or understand another person, and the patient might also experience it as destructive if the phenomenologist presumes to have captured the entire subjectivity of the patient in a too definitive and totalizing fashion. ${ }^{17}$ The informants stressed the importance of being honest about their difficulty of following or understanding the patients. This type of honesty or disclosure is recommended for the maintenance of the empathic attunement. ${ }^{25,27}$

It has been suggested that it could be hard for the therapist to feel unrecognized by the patient as a consequence of the patient's difficulty with intersubjective processes. ${ }^{11}$ The informants seemed to manage this lack of personal recognition partly by the professional confirmation from theories of the nature of the psychopathological phenomena they observed. That the sadness sometimes emerges directly from being attuned to the patient's painful emotional states has also been noted previously. ${ }^{11}$

Affect attunement is assumed to lead to the growth of a more coherent self. Kohut described three important aspects of the attunement: "mirroring," "idealizing" and "likeness/twinship." ${ }^{30}$ The informants mostly seemed to address the mirroring aspect, although some idealizing also seemed to be at work in the expertise/admiration expressions.

Positive emotions like admiration have been described in the literature as one of the driving forces of therapist engagement, i.e., described as the charm of the poetry and the honest search for meaning expressed by the patients. ${ }^{31}$ The worry and insecurity has also been previously recognized as part of the job when working with patients with schizophrenia. The therapist needs to be thick-skinned or somewhat hardy, ${ }^{32}$ as they might experience disappointment due to the patient's unconscious thriving for the doctor's failure as part of their unconscious resentment and anger. ${ }^{25}$ The therapist might also experience insecurity due to the limitations of the scientific knowledge and treatment possibilities. ${ }^{25}$ The latter insecurity seemed to form the basis for a large part of the worry and sadness mentioned by the informants. Furthermore, the protraction of the process might induce despair. ${ }^{30}$

It has recently been suggested that CBT, due to its emphasis on metacognition, aggravates hyperreflectivity and perplexity. ${ }^{10,18,33}$ In CBT, the focus is on the establishment of a collaborative working relationship; the Socratic dialog is used to help the patients realize the content of their thoughts and see the lack of logic in their argumentation. CBT also aims at inspiring hope and it is conducted in a setting where an expert therapist directs the patient. ${ }^{34-36}$ Depending on the empathetic skills of 
the therapist, the CBT dialog could have the quality of sharing experience, but the confrontation inherent in the pin-pointing of illogicality, frequently combined with a teacher-like psychoeducative approach (and distance, ) has the potential to undermine the sharing of experience emphasized by the informants. ${ }^{18,33}$ As part of the homework in CBT, the patients are encouraged to list situations and analyze their own thoughts, feelings and behaviors. This mode of communication and the selfreflecting, objectifying stance involved in the cognitive analysis differ from the way the informants described their manner of relating expressions of hyperreflectivity and perplexity to the patients' emotions, life events and goals. In addition, the informants paid utmost attention to doing this in a curious and sensitive manner, with a focus on synthesis rather than analysis (see Table 1, third column: P3, 360).

Likewise, the described encouragement of sharing of experiences appears to be notably less confronting than the Socratic dialog. ${ }^{10}$

\section{Strengths and limitations}

The basic pre-conception of hyperreflectivity and perplexity as psychopathological phenomena of schizophrenia spectrum disorders was not questioned in this study. If this premise is not accepted, the construct validity of the investigation could be at stake. The first author (SMA), who phrased the research questions and conducted the interviews, had previously carried out empirical research with a special emphasis on self-disorders and brain physiology. The researchers (SMA and ASD) were working clinically in psychiatry and they were trained in gestalt psychotherapy, hence the researchers as well as the informants were keenly interested in phenomenology. Perhaps the interventions could have been questioned further if the researchers had not been so familiar with the implications of the phenomenological terminology. Likewise, the researchers' background in experiential psychotherapy could have influenced the hermeneutic process, even while they thrived for unbiased reading and text analysis. ${ }^{37}$

Craftsmanship was achieved through previous training in empirical investigations (SMA) and research supervision by an experienced IPA researcher (ASD). Furthermore, the approach followed guidelines for qualitative research. Regrettably, feedback was not obtained from more than one informant, despite several attempts. All the informants were given the résumé of the results for comments and the possibility for coauthorship. One informant wished to do so (PM). Within the field of clinical phenomenological research, the selected informants seemed to be a reasonable sample. It was not possible to obtain more participants, and considering the narrow field of the study and the applied analysis, which is highly suited for small scale purposeful sampling, the emerging themes were considered relevant.

\section{Conclusion}

We delineated important aspects of the therapeutic meeting between patients with schizophrenia spectrum disorders and clinical researchers who consider the patient's condition to be self-disorders (including perplexity and hyperreflectivity). In accordance with recent phenomenological psychotherapy case studies, the approaches described as sharing experiences and linking hyperreflections to real life and emotions were the major interventions described in the present material. Further studies are necessary to address in a quantitative manner whether these approaches are superior to other therapeutic interventions in the treatment of the self-disordered patient.

The list of primary themes covers what might seem very basic therapeutic interventions. However, the careful and open-minded manner in which these were carried out was noteworthy. The double task of staying closely attuned to the patient's airy reflections and, at the same time, when the patient was ready for it, of carefully making links to domains of the patient's everyday life, was clearly molded to patients with fragile attachment.

\section{Disclosure}

No conflicts of interest declared concerning the publication of this article.

\section{References}

1. Bachmann S, Resch F, Mundt C. Psychological treatments for psychosis: history and overview. J Am Acad Psychoanalysis Dyn Psychiatr. 2003;31:155-76.

2. Alanen YO, Armelius B-A, Lehtinen K, Rosenbaum B, Sjöström R, Ugelstad $E$, editors. Early treatment for schizophrenic patients. Scandinavian psychotherapeutic approaches. Oslo: Scandinavian University Press; 1994.

3. Spaulding W, Nolting J. Psychotherapy for schizophrenia in the year 2030: prognosis and prognostication. Schizophr Bull. 2006;32 Suppl 1:S94-105.

4. Alanen YO. Schizophrenia: Its origins and need-adapted treatment. London: Karnac Books; 1997.

5. Mundt C. Anomalous self-experience: a plea for phenomenology. Psychopathology. 2005;38:231-5.

6. Parnas J, Jansson L, Sass L, Handest P. Self-experience in the prodromal phases of schizophrenia: a pilot study of first admissions. Neurol Psychiatry Brain Res. 1998;6:97-106. 
7. Møller $\mathrm{P}$, Husby $\mathrm{R}$. The initial prodrome in schizophrenia: searching for naturalistic core dimensions of experience and behavior. Schizophr Bull. 2000;26:217-32.

8. Parnas J, Møller P, Kircher T, Thalbitzer J, Jansson L, Handest $P$, et al. EASE: Examination of Anomalous Self-Experience. Psychopathology. 2005;38:236-58.

9. Sass LA, Parnas J. Explaining schizophrenia: the relevance of phenomenology. In: Chung M, Fulford KWM, Graham G, editors. Reconceiving schizophrenia. Oxford: Oxford University Press; 2006. p. 63-97.

10. Nelson B, Sass LA, Skodlar B. The phenomenological model of psychotic vulnerability and its possible implications for psychological interventions in the ultra-high risk ('prodromal') population. Psychopathology. 2009;42:283-92.

11. Rosenbaum B, Harder S. Psychosis and the dynamics of the psychotherapy process. Int Rev Psychiatry. 2007;19:13-23.

12. Lysaker $\mathrm{PH}$, Daroyanni P. Facilitating the emergence of interpersonal relatedness in individual psychotherapy of schizophrenia: a case study. Bull Menninger Clin. 2006;70:53-66.

13. Lysaker P, Buck K, Fogley R, Ringer J, Harder S, Hasson-Ohayon $I$, et al. The mutual development of intersubjectivity and metacognitive capacity in the psychotherapy for persons with schizophrenia. J Contemp Psychother. 2013;43:63-72.

14. Stanghellini G, Lysaker P. The psychotherapy of schizophrenia through the lens of phenomenology: intersubjectivity and the search for the recovery of first- and second-person awareness. Am J Psychother. 2007;61:163-79.

15. Pérez-Álvarez $M$, García-Montes J, Vallina-Fernández $O$, Perona-Garcelán S, Cuevas-Yust C. New life for schizophrenia psychotherapy in the light of phenomenology. Clin Psychol Psychother. 2011;18:187.

16. Hamm JA, Leonhardt BL. The role of interpersonal connection, personal narrative, and metacognition in integrative psychotherapy for schizophrenia: a case report. J Clin Psychol. 2016;72:13241.

17. Nelson B, Sass LA. Medusa's stare: a case study of working with self-disturbance in the early phase of schizophrenia. Clin Case Stud. 2009;8:489-504.

18. Nelson B, Raballo A. Basic self-disturbance in the schizophrenia spectrum: taking stock and moving forward. Psychopathology. 2015;48:301-9.

19. Smith JA, Jarman M, Osborn M. Doing interpretative phenomenological analysis. In: Chamberlain K, editor. Qualitative health psychology theories and methods. London: SAGE Publications; 1999. p. 51-80.

20. Meho LI. E-mail interviewing in qualitative research: a methodological discussion. J Am Soc Inf Sci Technol. 2006;57:1284-95.

21. Clarke $\mathrm{P}$. The internet as a medium for qualitative research. S Afr J Inf Manag. 2000;2.

22. Bampton R, Cowton CJ. The E-interview. FQS - Forum Qualitative Sozialforschung. $2002 ; 3$.
23. Hallberg M. Hermeneutik. In: Erikson MG, editor. Vetenskabsteori för psykologi og andra samhällsvetenskapar. Lund: Studentlitteratur; 1999. p. 73-99.

24. Smith JA, Osborn M. Interpretative phenomenological analysis. In: Smith JA, editor. Qualitative psychology. London: SAGE Publications Ltd; 2003. p. 51-80.

25. Selzer MA, Sullivan TB, Carsky M, Terkelsen KG. Working with the person with schizophrenia. The treatment alliance. New York/ London: New York University Press; 1989.

26. Nischk Dölker C, Rusch J, Merz P. From theory to clinical practice: a phenomenologically inspired intervention for patients with schizophrenia. Psychopathology. 2015;48:127-36.

27. Vinogradov S, Yalom ID, editors. Treating schizophrenia. San Fransisco: Jossey-Bass Publishers; 1995.

28. Brent B. Mentalization-based psychodynamic psychotherapy for psychosis. J Clin Psychol. 2009;65:803-14.

29. Benedetti G. Psychotherapy of schizophrenia. New Jersey: Jason Aronson; 1995.

30. Kohut $\mathrm{H}$. The restoration of the self. Chicago: University of Chicago Press; 2011.

31. Eldred S, Foster B, Gunderson JG, Mosher LR, Semrad O. Process of psychotherapy of schizophrenia. In: Gunderson JG, Mosher LR, editors. Psychotherapy of schizophrenia. New York: Jason Aronson; 1975. p. 22-41.

32. Silverstein SM, Spaulding WD, Menditto AA. Schizophrenia. Wedding D, editor. Göttingen \& Toronto: Hogrefe \& Huber; 2006.

33. Škodlar B, Henriksen MG, Sass LA, Nelson B, Parnas J. Cognitivebehavioral therapy for schizophrenia: a critical evaluation of its theoretical framework from a clinical-phenomenological perspective. Psychopathology. 2013;46:249-65.

34. Phillips LJ, Francey SM, Leicester SB, Bechdolf A, Morrison AP. Development of psychotherapy in the pre-psychotic phase. In: Gleeson JFM, Killackey E, Krstev H, editors. Psychotherapies for the psychoses, theoretical, cultural, and clinical integration. Hove East Sussex/New York: Routledge; 2008. p.117-34.

35. Turkington D, Kingdon D, Weiden PJ. Cognitive behavior therapy for schizophrenia. Am J Psychiatry. 2006;163:365-73.

36. Fowler D, Garety P, Kuipers E. Cognitive behaviour therapy for psychosis. Chichester: John Wiley \& Sons Ltd; 1995.

37. Smith JA. Beyond the divide between cognition and discourse: Using interpretative phenomenological analysis in health psychology. Psychol Health. 1996;11:261-71.

\section{Correspondence:}

Sidse Marie Arnfred, MD, PhD, DMSc, MSc Gestaltpsychotherapy Psychiatry West, Faelledvej 64200

Slagelse, Denmark

Tel.: +4524227045

E-mail: sidar@regionsjaelland.dk 